\title{
Effect of sintering temperature on structural and magnetic properties of $\mathrm{Mg}-\mathrm{Cu}-\mathrm{Zn}$ ferrite prepared by sol-gel method
}

\author{
A. Ashrafizadeh ${ }^{1}$, A. Ghasemi ${ }^{1}$, A. Paesano $\mathrm{Jr}^{2}, \mathrm{X} . \mathrm{Liu}^{1}, \mathrm{~A}$. Morisako ${ }^{1}$ \\ 1. Spin Device Technology Center, Faculty of Engineering, Shinshu University, Nagano, Japan \\ 2. Centro de Ciencias Exatas, Departmento de Fisica, Universidade Estadualde de Maringa, Parana, Brazil
}

\begin{abstract}
$\mathrm{Cu}_{0.5-\mathrm{x}} \mathrm{Mg}_{\mathrm{x}} \mathrm{Zn}_{0.5} \mathrm{Fe}_{2} \mathrm{O}_{4}(\mathrm{x}=0,0.1,0.2,0.3,0.4$ and 0.5$)$ ferrite prepared by sol-gel method and characterized. The samples were sintered at 1000,1100 and $1200^{\circ} \mathrm{C}$ for $4 \mathrm{~h}$. The effect of chemical composition and sintering temperature on structural and magnetic properties were investigated by X-ray diffraction (XRD), field emission scanning electron microscopy (FE-SEM), vibrating sample magnetometry (VSM) and susceptometer. The effect of substituting magnesium with copper in $\mathrm{Mg}-\mathrm{Zn}$ ferrite is to decrease the sintering temperature in order to obtain well crystalline samples. The grain size increases with increasing copper content and increasing sintering temperature have significant effect on it. Significant enhancement of grain growth was observed for samples with $\mathrm{x}=0-0.1$ which sintered at $1200^{\circ} \mathrm{C}$. Results show that copper content has significant influence on magnetic properties. Saturation magnetization increases with increasing of copper content at 1000 and $1100^{\circ} \mathrm{C}$ but at $1200^{\circ} \mathrm{C}$ increases up to $\mathrm{x}=0.2$ and then decreased. Coercive force was decreased by adding copper ions and effective magnetic susceptibility was increased by increasing of copper concentration.
\end{abstract}

Key words: ferrite, sol-gel, magnetic susceptibility, sintering temperature, coercivity

\section{Introduction}

$\mathrm{Mg}-\mathrm{Zn}$ ferrite is considered as one of the important magnetic material because of its high electrical resistivity, relatively high Curie temperature and low cost. However, the high sintering temperature of this ferrite makes it difficult to reach a sufficiently dense structure. By sintering at low temperature, energy consumption is minimized and material loss by evaporation is avoided [1]. It has been reported [2] that by substituting of $\mathrm{Mg}$ with $\mathrm{Cu}$ ions in $\mathrm{Mg}-\mathrm{Zn}$ ferrite, $\mathrm{Mg}-\mathrm{Cu}-\mathrm{Zn}$ ferrite can be sintered in lower sintering temperature without degrading the properties of material. Most previous investigations have synthesized $\mathrm{Mg}-\mathrm{Cu}-\mathrm{Zn}$ ferrite by solid-state reaction and reported that sintering at lower temperatures is possible by this method [3-5]. While this is the most common method, the products are not always stoichiometric and homogenous on microscopic scale [6]. The wet chemical methods seem to offer better properties. Aqueous sol-gel method has proved to be a successful technique for preparing different kinds of ferrite but just few research have been investigate the effect of this process on fabrication of $\mathrm{Mg}-\mathrm{Cu}-\mathrm{Zn}$ ferrite [7,8]. Since sol-gel method is simple, inexpensive and not requiring much time, compare to other wet processes, in the present work the $\mathrm{Mg}-\mathrm{Cu}-\mathrm{Zn}$ ferrite with different amount of $\mathrm{Cu}^{2+}$ ions was synthesized by this method and effect of copper content and sintering temperatures on microstructure and magnetic properties of $\mathrm{Cu}_{0.5 \times} \mathrm{Mgg}_{\mathrm{x}} \mathrm{Zn}_{0.5} \mathrm{Fe}_{2} \mathrm{O}_{4}(\mathrm{x}=0,0.1,0.2,0.3,0.4,0.5$ ) was evaluated.

\section{Experiments}

The $\mathrm{Mg}-\mathrm{Cu}-\mathrm{Zn}$ ferrites with composition of $\mathrm{Cu}_{0.5-\mathrm{x}} \mathrm{Mg}_{\mathrm{x}} \mathrm{Zn}_{0.5} \mathrm{Fe}_{2} \mathrm{O}_{4}$, (x vary from 0 to 0.5 with step of 0.1 ) were prepared by a sol-gel method. The aqueous sol was produced by disolving of iron nitrate, copper nitrate, magnesium nitrate and zinc nitrate, according of desired stoichiometric proportion, in deionized water and then mixed together by constant stirring. Citric acid was added to the sol for the enhancement of nitrates dissolution. The $\mathrm{pH}$ value of solution was adjusted to 7 using ammonia. All of the solutions were dark brown indicating, the presence of $\mathrm{Fe}^{3+}$ ions. The gels were obtained by slow evaporation at $70{ }^{\circ} \mathrm{C}$ until gel dried. Then, dried gels were sintered at 1000, 1100 and $1200{ }^{\circ} \mathrm{C}$ for $4 \mathrm{~h}$. Phase analysis was done by X-ray diffractometry (XRD) using $\mathrm{Cu} K \alpha$ radiation. The microstructures of the sintered ferrites were investigated by field emission scanning electron microscopy (FE-SEM). The magnetic properties were studied by vibrating sample magnetometry (VSM). Effective magnetic susceptibility variation versus dc magnetic field was measured for all samples by susceptometer Lake shore model 7000.

\section{Results and Disscussions}

\subsection{Structural features}

The XRD patterns of $\mathrm{Cu}_{0.5}{ }^{-} \mathrm{Mgg}_{\mathrm{x}} \mathrm{Zn}_{0.5} \mathrm{Fe}_{2} \mathrm{O}_{4}$ prepared by sol gel processing are shown in Fig. 1. It is obvious that by substituting $\mathrm{Mg}$ with $\mathrm{Cu}$, no extra peak corresponding to any second phase was identified. 


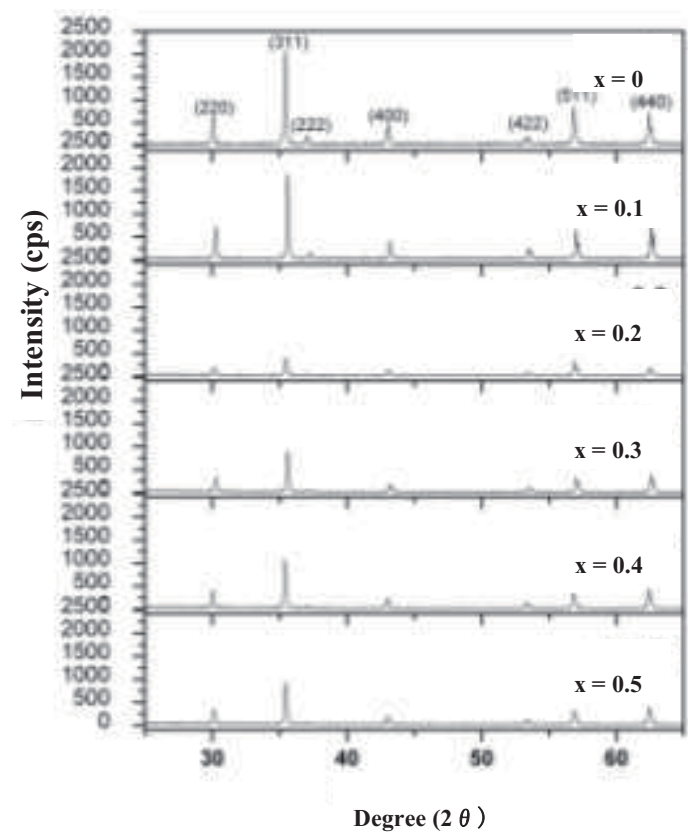

Fig. 1 XRD patterns of $\mathrm{Cu}_{0.5-\mathrm{x}} \mathrm{Mg}_{\mathrm{x}} \mathrm{Zn}_{0.5} \mathrm{Fe}_{2} \mathrm{O}_{4}$ prepared by sol gel processing.

Morphology and grain size of synthesized ferrites were investigated by FE-SEM. For all samples, dense structure was obtained. Results show that temperature and chemical composition can act as contributors on powder size. Fig. 2 presents the micrograph of samples sintered at $1100{ }^{\circ} \mathrm{C}$. The increase in grain size with increasing $\mathrm{Cu}$ content is clearly visible. Similar trend was obtained for temperature of 1000 and $1200{ }^{\circ} \mathrm{C}$ (which is not shown here). As can be seen, at chemical composition of $\mathrm{x}=0$ and $\mathrm{x}=0.1$ instantaneously enhancement in grain size is obtained. At these compositions, by sintering at 1100 and $1200^{\circ} \mathrm{C}$ shape of grain has changed from irregular to spherical. Moreover, at these conditions in grain boundaries liquid phase is observed which by increasing sintering temperature from 1100 to $1200^{\circ} \mathrm{C}$ amount of this phase have increased. It confirms that liquid phase sintering plays the main role in cation transportation between grain boundaries. The contribution of this phenomenon can be manipulated by enhancement of sintering temperature from 1000 to $1200^{\circ} \mathrm{C}$. In order to evaluate the evolution of mentioned phase, EDX analysis was employed. It is manifested that the incorporation of $\mathrm{Cu}$ cation through out of this zone is very alternative. Chemical analysis of other samples show that at lower amount of copper, chemical composition in all part of samples is homogenous and there is no difference between center and grain boundaries but for samples which possess high copper content, $\mathrm{Cu}$ rich precipitates are formed in boundaries (Fig. 3).
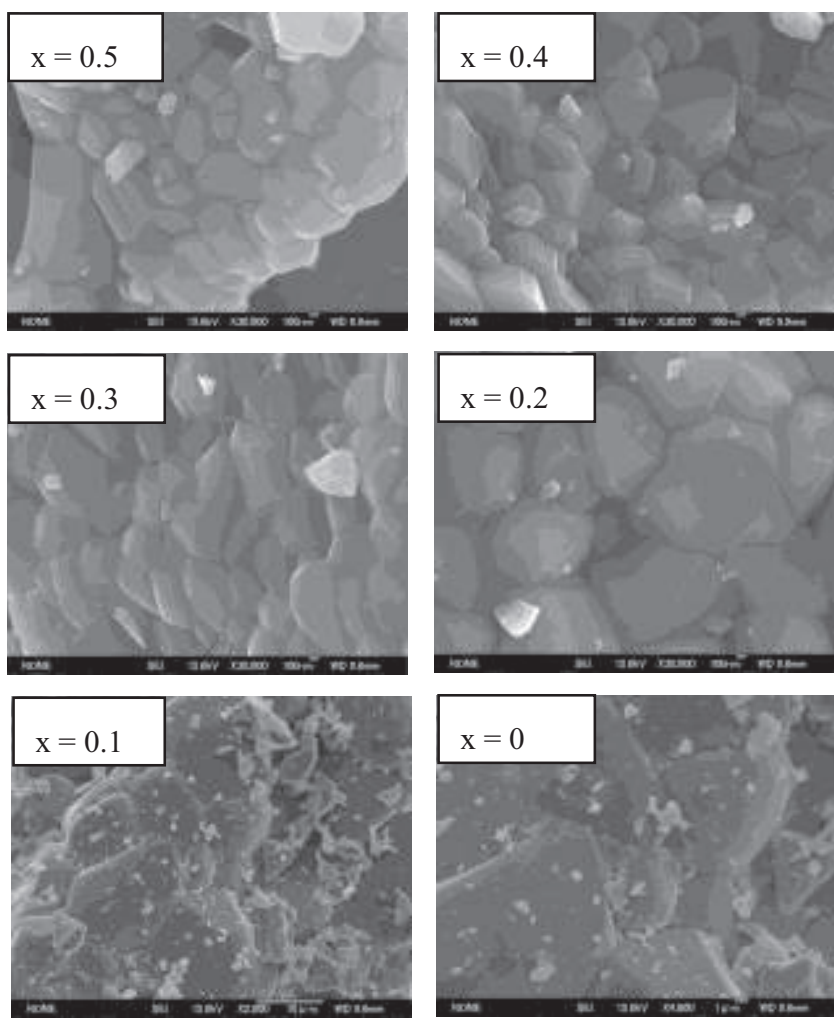

Fig. 2 FE-SEM micrograph of $\mathrm{Cu}_{0.5}{ }_{\mathrm{x}} \mathrm{Mg}_{\mathrm{x}} \mathrm{Zn}_{0.5} \mathrm{Fe}_{2} \mathrm{O}_{4}$ sintered at $1100^{\circ} \mathrm{C}$.
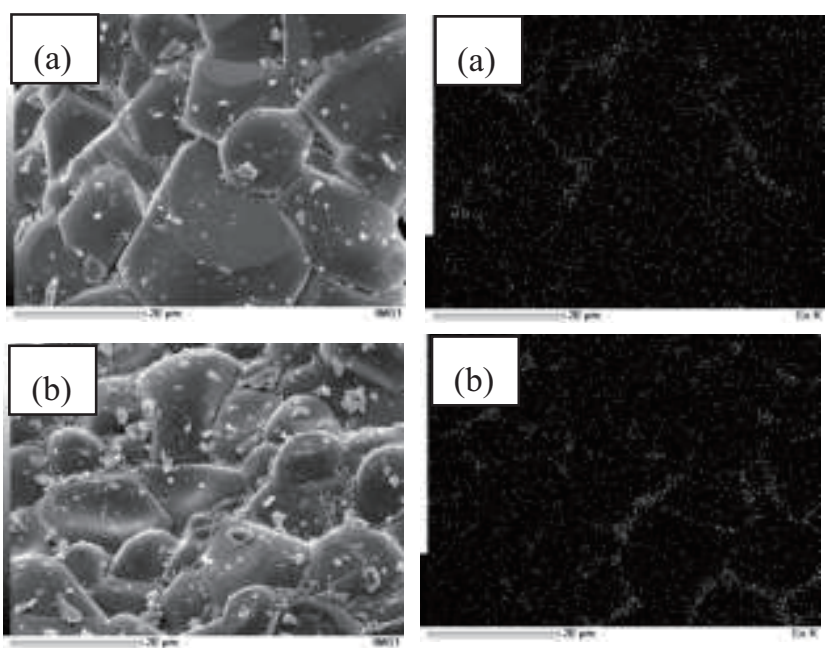

Fig. 3 Copper distribution in; (a) $\mathrm{Cu}_{0.4} \mathrm{Mg}_{0.1} \mathrm{Zn}_{0.5} \mathrm{Fe}_{2} \mathrm{O}_{4}$ (b) $\mathrm{Cu}_{0.5} \mathrm{Zn}_{0.5} \mathrm{Fe}_{2} \mathrm{O}_{4}$ sintered at $1200^{\circ} \mathrm{C}$.

\subsection{Magnetic properties}

The synthesized $\mathrm{Mg}-\mathrm{Cu}-\mathrm{Zn}$ ferrite showed a narrow S-shape hysteresis curve with high saturation magnetization and low coercivity. The hysteresis loops of samples prepared at $1100{ }^{\circ} \mathrm{C}$ are shown in Fig. 4a. Fig. $4 \mathrm{~b}$ shows the variation of saturation magnetization with composition at different sintering temperatures. For sintering at 1000 and $1100{ }^{\circ} \mathrm{C}$ similar trend is observed; by increasing copper content, $M_{S}$ has 
increased but at $1200^{\circ} \mathrm{C}, M_{s}$ increases up to $\mathrm{Cu}=0.2$ and then decreased. The variations of $M_{S}$ with chemical composition can be explained on the basis of the exchange interaction between the ions at the tetrahedral (A) and octahedral (B) sites. Mg-ferrite is a spinel with inversion degrees of about 0.8 [1], with

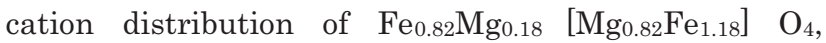
where brackets denote $\mathrm{B}$ sites. In the $\mathrm{Mg}-\mathrm{Cu}-\mathrm{Zn}$ ferrite, the stable $\mathrm{Zn}^{2+}$ ions occupy the A sites only and $\mathrm{Mg}^{2+}$, $\mathrm{Cu}^{2+}$ and $\mathrm{Fe}^{3+}$ ions have preference for the $\mathrm{B}$ site. The resultant magnetization is difference magnetization between magnetization of $\mathrm{A}$ and $\mathrm{B}$ sites. By substitution of $\mathrm{Mg}^{2+}$ with $\mathrm{Cu}^{2+}$ ions, since $\mathrm{Cu}^{2+}$ have a magnetic moment of $1 \mu_{\beta}$, magnetization in $\mathrm{B}$ site increase and this lead to increase of saturation magnetization. Decreasing of $M_{S}$ at $1200{ }^{\circ} \mathrm{C}$ for samples with high amount of copper may be attributed to formation of large amount of non-magnetic $\mathrm{Cu}$-rich precipitates between grains.

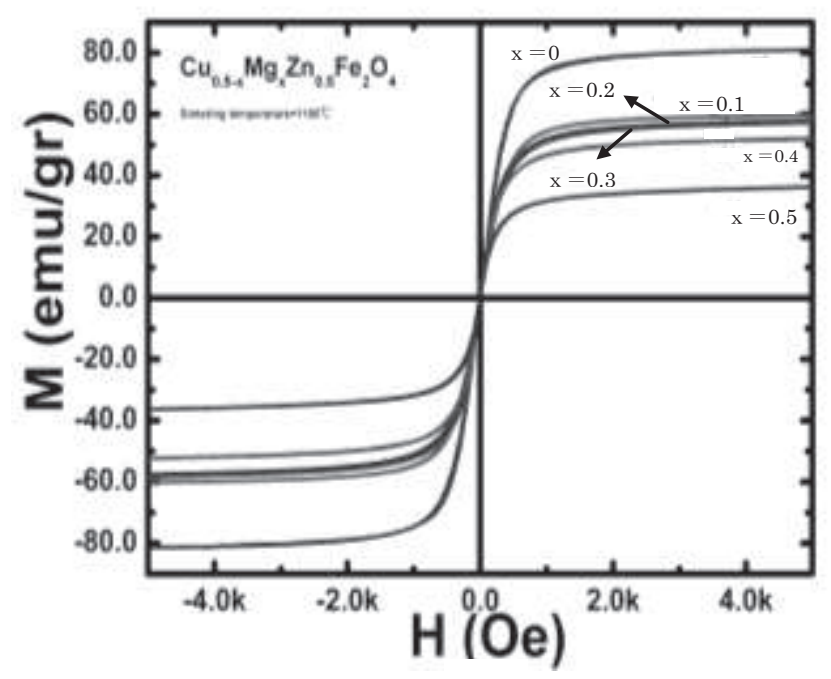

(a)

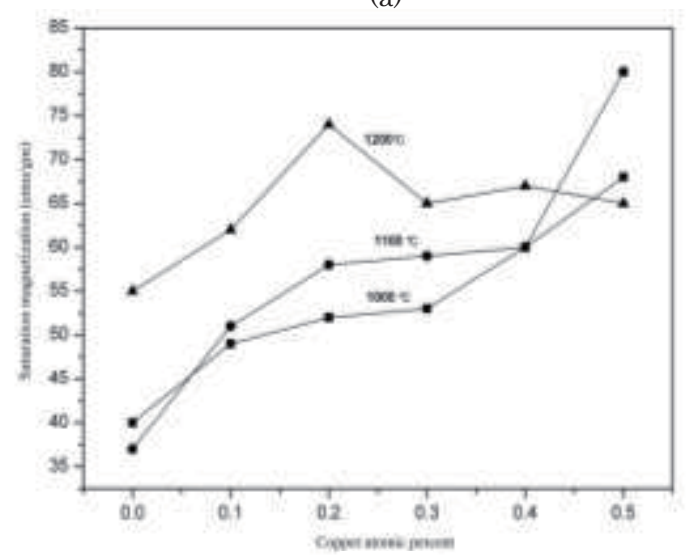

(b)

Fig. 4 (a) hysteresis curve of samples prepared at 1100 ${ }^{\circ} \mathrm{C}$, (b) Saturation magnetization variation versus copper content.

Figure 5 shows the variation of coercive force with chemical composition. It is obvious that by increasing copper content, $H_{c}$ has decreased. The relation of the coercivity with the grain size has been measured quantitatively. It seems to be linearly related to the reciprocal grain size. We turn now to discuss the relationship between the coercivity and the grain size. Basically, our result is consistent with previous reports, which have shown the fact that the coercivity of ferrite depends on the sintering temperature and the grain size $[9,10]$. Remarkably, however, the coercivity seems to be related to the reciprocal grain size. In a polycrystalline sample, the density of the grain boundary is in inverse proportion to the grain size. Accordingly, we conjecture that the pinning of magnetization at the grain boundaries is the most likely cause for determining the coercivity. If the grain size largely increases, however, the coercivity caused by grain boundary pinning will disappear because each grain can be multi-domain state. The coercivity of a multi-domain grain sample probably depends on the factors within grain rather than grain boundaries. Samples sintered at $1000^{\circ} \mathrm{C}$ contain many small grains. In a small grain sample, the grain boundaries can act as pinning centers, which lead to impede the domain wall motion and/or the domain nucleation. Since the grains of a few micron sizes are large enough to be multidomain state, the coercivity caused by intrinsic factors within grains should be very small.

Figure 6 indicates the variation of real part of effective magnetic susceptibility with $H_{\text {dc }}$ field for samples sintered at $1200{ }^{\circ} \mathrm{C}$. It is observed that effective magnetic susceptibility in all samples have linear change with increasing dc or ac field. The lowest values for the effective magnetic susceptibility were recorded for $\mathrm{x}=0.5$. It is well known that the domain wall is a region across which spins (elementary magnetic moment) change directions gradually owing to a compromise between magnetocrystalline anisotropy energy and exchange energy. The easy direction of the developed local induced anisotropy within a static wall in zero field coincides with the direction of the spin, and this results in an extra potential superimposed on the initial pinning potential wall resulting from other fixed sources, or an extra pinning force against the wall movements from its equilibrium position. The porosities and inhomogeneity are probably responsible for the domain wall pinning and the observed behavior in effective magnetic susceptibility. If there were no pinning centers in the samples, the domain walls would under the influence of external field take an equilibrium position with minimum energy. With pinning centers, domain walls are pinned in different positions and the field exerts a pressure on them tending to shift in to equilibrium position. The further away they are from the equilibrium position, the larger the pressure is. However, pinned domain walls can still move within the potential barrier of pinning centers. 
The smaller the pressure by the field, the larger the mobility of domain walls in the potential barrier. When a domain wall gets released from a pinning site under the combined influence of the dc field and the ac field, it will jump to a new stable position. In the new position, it will experience a smaller pressure due to the dc field than in the old position, resulting in an increased mobility of the domain wall in the new position. Jumping back to old sites will not occur because the pressure on the domain walls due to the dc or ac field pushes them in one direction only. After the jump, the domain walls only oscillate in new potential barriers, which is a reversible process. They do not have enough energy to jump continuously between the pinning sites.

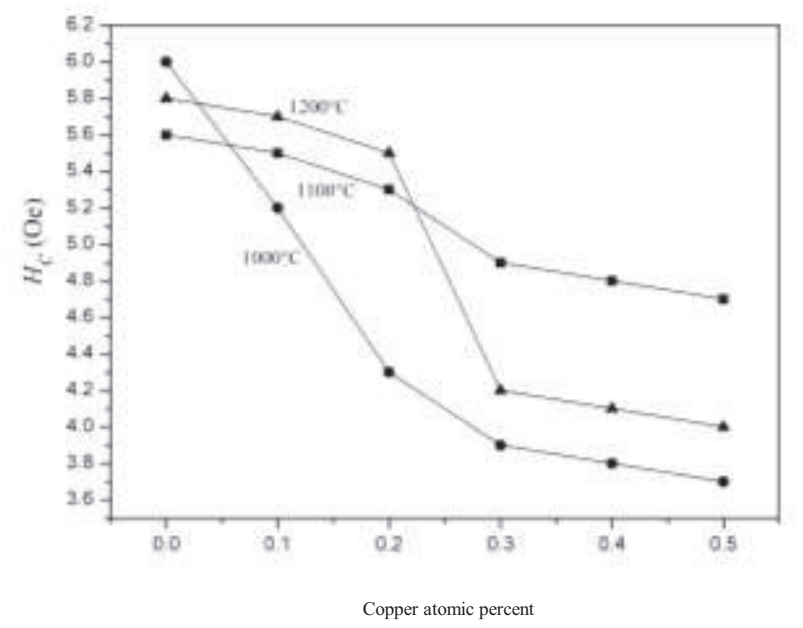

Fig. 5 Variation of coercive force versus copper content.

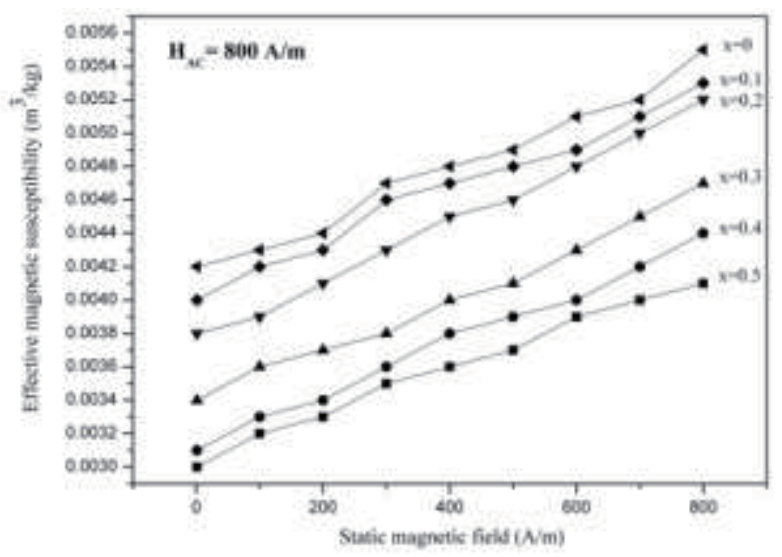

Fig. 6 Effective magnetic susceptibility versus dc magnetic field for samples prepared at $1200^{\circ} \mathrm{C}$

\section{Conclusions}

$\mathrm{Mg}-\mathrm{Cu}-\mathrm{Zn}$ ferrite by sol-gel method was synthesized and effect of copper content and sintering temperature on microstructure and magnetic properties were investigated. By substituting $\mathrm{Mg}$ with $\mathrm{Cu}$ in $\mathrm{Mg}-\mathrm{Zn}$ ferrite, dense $\mathrm{Mg}-\mathrm{Cu}-\mathrm{Zn}$ ferrite with low sintering temperature with formation of no secondary phase can be obtained. Grain size is found to increase significantly with increasing copper content. Saturation magnetization has increased by both increasing of copper content and sintering temperature. It is observed that effective magnetic susceptibility in all samples have linear change with increasing dc or ac field.

Acknowledgements This work was supported in part by Grant-in-Aid for JSPS Fellows from Japan Society for Promotion of Science (JSPS) and Grants-in-Aid for Scientific Research (B).

\section{References}

1) M. Manjurul Haque, M. Huq, and M. A. Hakim: Mater. Chem. Phys., 112, 580 (2008).

2) E. Rezlescu, N. Rezlescu, P.D. Popa, L. Rezlescu, C. Pasnicu, and M.L. Craus: Mater. Res. Bull., 33, 915 (1998).

3) M. Manjurul Haque, M. Huq, and M. A. Hakim: J. Magn. Magn. Mater., 320, 2792 (2008).

4) N. Rezlescu, E. Rezlescu, P.D. Popa, M.L. Craus, and L. Rezlescu: J. Magn. Magn. Mater.,182, 199 (1998)

5) S. R. Murthy: Bull. Mater. Sci., 24, 379 (2001).

6) A. Verma, T.C. Goel, R.G. Mendiratta, and P. Kishan: J. Magn. Magn. Mater.,208,13 (2000).

7) Z. Yue, J. Zhou, L. Li, X. Wang, and Z. Gui: Mater. Sci. Eng., B86, 64 (2001).

8) Z. Yue, J. Zhou, X. Wang, Z. Gui, and L. Li: J. Mater. Sci. Lett., 20, 1327 (2001).

9) A. Ghasemi, and A. Morisako: J. Alloy comp. 456, 485 (2008).

10) A. Ghasemi, A. Hossienpour, A. Morisako, A. Saatchi and M. Salehi: J. Magn. Magn. Mater. 302, 429 (2006).

Received Oct. 20, 2009; Revised Feb. 28, 2010; Accepted May. 20,2010 